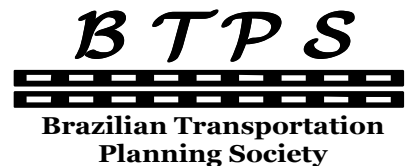

Planning Society

\author{
Journal of Transport Literature \\ Vol. 8, n. 1, pp. 265-284, Jan. 2014 \\ Research Directory
}

JTL | RELIT

www.transport-literature.org ISSN 2238-1031

\title{
Transporte coletivo urbano: uma análise de demanda para a cidade de Salvador
}

[Urban public transportation: a demand analysis for the city of Salvador]

\author{
Mayara Condé Rocha Murça*, Carlos Müller \\ Instituto Tecnológico de Aeronáutica - Brasil
}

Submitted 14 Jun 2012; received in revised form 14 Jan 2013; accepted 20 Jan 2013

\begin{abstract}
Resumo
Este trabalho consiste na realização de um estudo sobre a demanda de transporte coletivo urbano por ônibus no contexto da cidade de Salvador. Foram especificados três modelos econométricos, os quais foram testados e comparados entre si. Verificouse que a agregação de variáveis é um possível caminho para minimizar problemas de multicolinearidade identificados e que o aperfeiçoamento da modelagem matemática possibilitou uma melhoria significativa da qualidade do ajuste, mantendo-se a significância estatística dos parâmetros. Como resultado, obteve-se que a elasticidade da demanda com relação ao rendimento médio per capita foi de 1,44\% (estatisticamente significante a 1\%) e, com relação à tarifa, foi de $-0,06 \%$ (estatisticamente significante a 10\%), revelando um comportamento inelástico para esta variável. Quando comparado ao trabalho de Carvalho e Pereira (2012), isto indica que as diferenças na estrutura urbana das cidades devem ser levadas em consideração, sendo necessários estudos de demanda individuais para cada cidade. Por fim, foram realizadas previsões no curto prazo considerando cenários de evolução das variáveis analisadas.
\end{abstract}

Palavras-Chave: demanda, transporte público, ônibus, salvador, econometria.

\begin{abstract}
This paper aims to perform a study on the demand for urban public transportation by bus in the context of the city of Salvador. Three econometric models were specified, tested and compared between each other. It was found that the aggregation of variables is one possible way to minimize multicollinearity problems and that improvements in the mathematical modeling enabled a significant improvement in the goodness of fit, maintaining the statistical significance of the parameters. As a result, it was found that the elasticity of the demand in relation to average per capita income was $1.44 \%$ (statistically significant at $1 \%$ ) and, in relation to tariff, it was $-0.06 \%$ (statistically significant at $10 \%$ ), revealing an inelastic behavior for this variable. When compared to the work of Carvalho and Pereira (2012), it indicates that the differences in the urban structure of cities should be taken into consideration and that individual studies for each city are necessary. Finally, forecasting in the short term was developed considering evolution scenarios of the analyzed variables.
\end{abstract}

Key words: demand, public transportation, bus, salvador, econometrics.

*Email: may.crm@gmail.com.

\section{Recommended Citation}

Murça, M. C. R. and Müller, C. (2014) Transporte coletivo urbano: uma análise de demanda para a cidade de Salvador. Journal of Transport Literature, vol. 8, n. 1, pp. 265-284.

- JTL/RELIT is a fully electronic, peer-reviewed, open access, international journal focused on emerging transport markets and published by BPTS - Brazilian Transport Planning Society. Website www.transport-literature.org. ISSN 2238-1031. 


\section{Introdução}

Este trabalho consiste na realização de um estudo econométrico sobre a demanda de transporte coletivo urbano por ônibus no contexto da cidade de Salvador. A análise e previsão de demanda de setores estratégicos para a economia é um dos itens essenciais no processo de planejamento de investimentos em um país. Em função das necessidades de mobilidade inerentes ao desenvolvimento das atividades produtivas da sociedade, o setor de transportes indubitavelmente merece a atenção de todas as esferas governamentais. No contexto brasileiro, o crescimento populacional e o processo acelerado de urbanização ocorrido após a década de 1950 não foram acompanhados pela expansão da infraestrutura na mesma ordem de grandeza e de forma organizada, gerando problemas que permeiam a realidade urbana até os dias atuais. Como exemplo, na maioria das cidades, a pequena diversificação da matriz modal e as restrições de capacidade dos meios de transporte públicos eventualmente disponíveis revelam a recorrente insuficiência de planejamento destinado à priorização e alocação de investimentos.

Além das carências advindas do contexto histórico e das necessidades oriundas do processo hodierno de desenvolvimento, dois eventos internacionais de grande porte - a Copa do Mundo de 2014 e as Olimpíadas de 2016 - pressionam o país em direção a mudanças de postura estratégica. No que diz respeito ao setor de transportes, estudos detalhados de demanda e capacidade tornar-se-ão indispensáveis nas diversas microrregiões nacionais, a fim de sustentar tomadas de decisão capazes de eliminar gargalos de forma a atender a demanda potencial e, de maneira mais ampla, alavancar o progresso e prover o bem-estar social. Nesse sentido, este trabalho teve o objetivo de analisar o comportamento da demanda pelo meio de transporte coletivo urbano predominante no país - o ônibus - no contexto de uma das cidades sede da Copa do Mundo de 2014 - Salvador - e, assim, viabilizar a discussão de variáveis relevantes e a realização de previsões no curto prazo.

A econometria é uma abordagem utilizada para modelar matematicamente conceitos populacionais a partir de amostras. O maior desafio desta técnica reside no entendimento do processo gerador de dados e na determinação das variáveis que efetivamente explicam o conceito que está sendo investigado. Na literatura nacional e internacional, a maioria dos 
estudos aponta que o poder aquisitivo da população, o preço do transporte público e o grau de produtividade do município são fatores determinantes na demanda por transportes.

No contexto nacional, Lopes Filho (2003) utilizou as variáveis matrículas escolares ofertadas, renda média domiciliar e empregos ofertados para realizar a previsão de demanda por ônibus na cidade de Fortaleza em um modelo linear de geração de viagens, obtendo uma significância estatística de 5\% para essas variáveis e uma qualidade do ajuste de 0,98. Já Carvalho e Pereira (2012) estudaram os efeitos da variação da tarifa e da renda da população sobre a demanda de transporte público coletivo urbano em nove capitais brasileiras através de um modelo linear e obtiveram que estas variáveis foram estatisticamente significantes a $1 \%$ e que a qualidade do ajuste foi de 0,94 . Terrabuio Junior (2010) analisou o comportamento da demanda por transporte coletivo urbano em quatro cidades do interior de São Paulo e desenvolveu modelos de regressão linear múltipla visando estabelecer relação entre a mesma e as seguintes variáveis socioeconômicas: população, índice de motorização e PIB per capita.

No contexto internacional, Souche (2010) avaliou o custo médio de uma viagem com veículo particular, o custo médio de uma viagem com transporte público, a disponibilidade de transporte público, a renda e a estrutura urbana como determinantes estruturais da demanda por transporte público urbano e obteve que apenas os custos dos modais e a estrutura urbana são estatisticamente significantes. Por outro lado, Holmgren (2007) recomenda que os modelos de demanda por transporte público também incluam uma métrica de nível de serviço oferecido, apesar da dificuldade de determinação desta variável na prática.

Neste trabalho, analisou-se a influência do tamanho da população economicamente ativa, do rendimento médio per capita e do preço da passagem na demanda por ônibus urbano na cidade de Salvador através de um estudo econométrico, desenvolvendo-se um modelo de previsão para este meio de transporte coletivo. Para isso, foi composta uma base de dados, a qual foi descrita qualitativa e quantitativamente. No que diz respeito ao estudo econométrico, foi possível testar se a agregação de variáveis que apresentam elevada correlação, nesse caso, aquelas relacionadas à população economicamente ativa e ao rendimento médio per capita, é uma possível solução para um problema de multicolinearidade identificado. Além dos modelos de regressão múltipla comumente utilizados na literatura da área, em que a variável dependente é a quantidade de passageiros transportados, especificou-se um modelo oriundo da hipótese de cada passageiro transportado é consequência da aplicação de um modelo de 
frequência de viagens sobre cada integrante da população economicamente ativa, o qual se revelou superior aos demais em termos de qualidade do ajuste e com significância estatística dos parâmetros.

Como resultado, obteve-se que, para cada $1 \%$ de aumento no rendimento médio per capita, a demanda cresce $1,44 \%$ e que, para cada $1 \%$ de aumento real no valor da tarifa, a demanda decresce $0,06 \%$ (comportamento inelástico). É válido observar que este resultado contraria as conclusões de Carvalho e Pereira (2012) no que diz respeito à tendência de comportamento elástico da demanda por transporte público urbano desde 2001 (demanda agregada para nove capitais brasileiras), indicando que as diferentes estruturas urbanas das cidades influenciam o comportamento da demanda, devendo, portanto, ser analisadas individualmente. Ainda, foram desenhados cenários que resultaram em uma previsão de crescimento de 19,2\% na quantidade de passageiros em 5 anos.

Para cumprir os objetivos supracitados, este trabalho foi assim dividido: na Seção 1, apresenta-se o histórico de desenvolvimento do transporte público em Salvador; na Seção 2, é realizada a descrição da base de dados utilizada no estudo econométrico, o qual é apresentado na Seção 3 e, finalmente, na Seção 4, é realizada a previsão de demanda para um horizonte de 5 anos.

\section{Histórico do transporte público em Salvador}

Segundo o Sindicato das Empresas de Transporte de Passageiros de Salvador - SETPS (2012a), a história do transporte na cidade começou em meados de 1845, quando foi concedido o privilégio de se estabelecer companhias de ônibus ou gôndolas (veículos puxados por quatro animais) através da Lei Municipal. Em 1864, foram criadas algumas linhas de veículos sobre trilhos e aprovadas as concessões para os serviços de passageiros entre a Cidade Alta e a Cidade Baixa e, em 1912, a operação dos ônibus em Salvador foi iniciada, mas de modo precário. Em 1955, a Prefeitura Municipal baixou um decreto considerando em crise os serviços coletivos de transporte e, seis anos depois, os bondes foram condenados, sendo extintos e substituídos pouco a pouco pelos ônibus. Com a expansão do sistema de ônibus nos anos seguintes, houve a regulamentação do serviço de transporte coletivo em 1971 e, a partir daí, foi desenvolvida uma série de Estudos, Planos e Projetos de Transporte para a 
cidade. Com o objetivo de promover melhorias no sistema de transporte por ônibus, em 1992, houve uma intensa renovação da frota, com a aquisição de novos e modernos veículos e, em 1996, o SETPS iniciou o processo de bilhetagem eletrônica, implantando a tecnologia do cartão inteligente.

De acordo com a última pesquisa O/D realizada em 2002, o modal de transporte mais utilizado em Salvador é o ônibus, o qual representa $52 \%$ das viagens. O modo a pé corresponde por $28 \%$, as viagens por automóvel representam 14\%, os modos ferroviário e hidroviário correspondem por $1 \%$ cada um e os demais modos representam $3 \%$ das viagens (Santos, 2012).

A operação das linhas de ônibus ocorre através de permissão, concedida às empresas de transporte que compõem o SETPS. O FUNDETRANS, criado através da Lei Municipal $\mathrm{n}^{\circ}$ 4534/92, é responsável por promover o desenvolvimento e a modernização do Sistema de Transporte Coletivo por Ônibus (STCO) no município de Salvador, bem como gerenciar o processo de compensação tarifária entre as empresas operadoras do STCO (Transalvador, 2012). Em 2012, foi anunciado o processo de concessão das linhas de ônibus em Salvador, com o objetivo de melhorar a situação do sistema de transportes na cidade (Celestino, 2012).

Atualmente, há integração tarifária aberta através de bilhetagem eletrônica ("Salvador Card") para passageiros que utilizem dois ônibus de zonas diferentes em uma viagem, em até uma hora (SETPS, 2012b). A integração tarifária também acontece através do Subsistema Local Integrado de Transportes (SLIT) por meio dos "amarelinhos", que levam os usuários dos bairros aos principais corredores de tráfego da cidade, permitindo o acesso aos ônibus convencionais. Ainda, há propostas para o STCO no município de Salvador nos níveis estrutural (macroacessibilidade - grandes demandas), auxiliar (médias demandas) e local (microacessibilidade - coleta e distribuição local).

Além do STCO, Salvador possui também quatro ascensores que ligam a Cidade Alta à Cidade Baixa: o Elevador Lacerda, o Plano Inclinado Gonçalves, o Plano Inclinado Liberdade Calçada - e o Plano Inclinado do Pilar (Santos, 2012). A linha ferroviária urbana, gerenciada pelo município, possui extensão de 13,6 km e oito estações (Calçada, Lobato, Almeida Brandão, Itacaranha, Praia Grande, Periperi, Coutos e Paripe). Finalmente, há um subsistema hidroviário que opera na Baía de Todos os Santos, atendendo à demanda de transporte 
municipal (entre São Thomé de Paripe e a Ilha da Maré) e intermunicipal (entre Salvador e a Ilha de Itaparica).

Futuramente, Salvador irá contar também com um metrô para complementar o sistema de transporte urbano. A linha 1, a qual vem sendo construída há mais de dez anos, está dividida em duas etapas: a primeira, que liga a Estação da Lapa ao Acesso Norte, e a segunda, que liga o Acesso Norte até Pirajá (Santos, 2012). Já a linha 2, projeto que integra o Programa de Aceleração do Crescimento (PAC) do Governo Federal, interligará o município de Lauro de Freitas a Salvador e contará com $22 \mathrm{~km}$, passando por importantes corredores urbanos, como a Avenida Paralela, e integrando-se com linhas de BRT nas vias alimentadoras e de ônibus convencional.

Pelo exposto, verifica-se que a matriz modal da cidade de Salvador apresenta baixa diversificação atualmente e que há uma forte dependência do transporte coletivo por ônibus. Apesar da existência de projetos para a complementação do sistema de transporte urbano, o ônibus deverá permanecer como modal predominante nos próximos anos, exigindo investimentos para ampliação da capacidade e melhoria do nível de serviço oferecido.

\section{Descrição da base de dados}

Com o objetivo de compor a base de dados necessária para o estudo econométrico de demanda por ônibus urbano, foram utilizadas as séries históricas de periodicidade mensal apresentadas na Tabela 1, no contexto da Região Metropolitana de Salvador. 
Tabela 1 - Séries históricas componentes da base de dados ${ }^{1}$

\begin{tabular}{|c|c|c|}
\hline Série histórica & Período & Fonte \\
\hline $\begin{array}{l}\text { Número de passageiros transportados por ônibus } \\
\text { independentemente do valor da tarifa }\end{array}$ & $\begin{array}{c}\text { Fev/1996 a } \\
\text { Jul/2011 }\end{array}$ & $\begin{array}{l}\text { FIPE }^{1} \\
(2012)\end{array}$ \\
\hline População economicamente ativa com 10 anos ou mais de idade & $\begin{array}{l}\text { Mar/2002 a } \\
\text { Mar/2012 }\end{array}$ & $\begin{array}{l}\mathrm{IBGE}^{2} \\
(2012)\end{array}$ \\
\hline $\begin{array}{l}\text { Rendimento médio real do trabalho principal, habitualmente } \\
\text { recebido por mês, pelas pessoas de } 10 \text { anos ou mais de idade, } \\
\text { ocupadas no trabalho principal da semana de referência }\end{array}$ & $\begin{array}{l}\text { Mar/2002 a } \\
\text { Mar/2012 }\end{array}$ & $\begin{array}{l}\text { IBGE } \\
(2012)\end{array}$ \\
\hline Média de IPCA - ônibus urbano & $\begin{array}{l}\mathrm{Jan} / 1996 \mathrm{a} \\
\mathrm{Abr} / 2012\end{array}$ & $\begin{array}{l}\text { IBGE } \\
(2012)\end{array}$ \\
\hline Média de IPCA - índice geral & $\begin{array}{c}\text { Jan/1996 a } \\
\text { Abr/2012 }\end{array}$ & IBGE \\
\hline
\end{tabular}

${ }^{1}$ Dados do Índice de Desempenho Econômico do Transporte (IDET)

${ }^{2}$ Dados do Sistema IBGE de Recuperação Automática (SIDRA)

Em função das séries históricas disponíveis e da abrangência temporal das mesmas, este trabalho limitou-se ao período de março de 2002 a julho de 2011 e foram utilizadas as seguintes variáveis para a construção dos modelos econométricos:

- $\quad$ pax - número de passageiros transportados por ônibus independentemente do valor da tarifa

- $p e a$ - população economicamente ativa com 10 anos ou mais de idade

- rend - rendimento médio real do trabalho principal, habitualmente recebido por mês, pelas pessoas de 10 anos ou mais de idade, ocupadas no trabalho principal

- tarifa - proxy para o preço da passagem, obtida através da série acumulada de média de IPCA relativo ao ônibus urbano deflacionada pela média geral de IPCA e normalizada para o valor atual da tarifa de ônibus em Salvador $(\mathrm{R} \$ 2,50)$

Através da geração de estatísticas descritivas e gráficos, foi possível realizar a discussão qualitativa da base de dados. As Figuras 1, 2, 3 e 4 apresentam o comportamento das variáveis pax, pea, rend e tarifa ao longo do período de tempo analisado. Observa-se que a quantidade de passageiros transportados por ônibus apresentou um comportamento bastante irregular, com presença de sazonalidade. Por outro lado, a população economicamente ativa e o rendimento médio mensal da mesma revelaram variações de menor intensidade, bem como uma tendência de crescimento no período. O comportamento da tarifa ilustra bem a situação do mercado de transporte público urbano por ônibus no Brasil, no qual os incrementos

\footnotetext{
${ }^{1}$ Fonte: autora.
} 
tarifários são pontuais e resultantes não apenas de aspectos econômicos, como também de questões políticas. Isto pode ser observado pelo formato do gráfico da Figura 4, no qual há incrementos pontuais na tarifa e declínio subsequente oriundo da perda de valor relativo em comparação com o restante dos bens de consumo regidos pela inflação.

Segundo Carvalho e Pereira (2012), em seu estudo sobre o efeito da variação da tarifa e da renda da população sobre a demanda de transporte público coletivo urbano em nove capitais brasileiras, houve um aumento acentuado nas tarifas de ônibus urbanos no período de 1995 a 2008 em detrimento do aumento dos custos operacionais do setor, à exceção de São Paulo, que cobre cerca de $20 \%$ dos custos do sistema com recursos orçamentários da prefeitura (segundo os autores, houve um aumento real superior a $70 \%$ no preço do óleo diesel nos últimos 15 anos, por exemplo). Através da Figura 4, é possível observar esta tendência de crescimento da tarifa.

Ainda de acordo com Carvalho e Pereira (2012), até 2001, este crescimento da tarifa não foi acompanhado pelo aumento da renda da população, o que resultou no comportamento elástico da demanda nesse período e na tendência de redução da demanda pagante. A partir de 2003, a recuperação da renda média domiciliar associada à introdução de políticas públicas tais como os programas de integração tarifária são alguns dos fatores que explicam a retomada do crescimento da demanda por ônibus urbano no Brasil. Percebe-se, assim, que a observação de tendências no comportamento da demanda pode ser obtida ao nível agregado. 


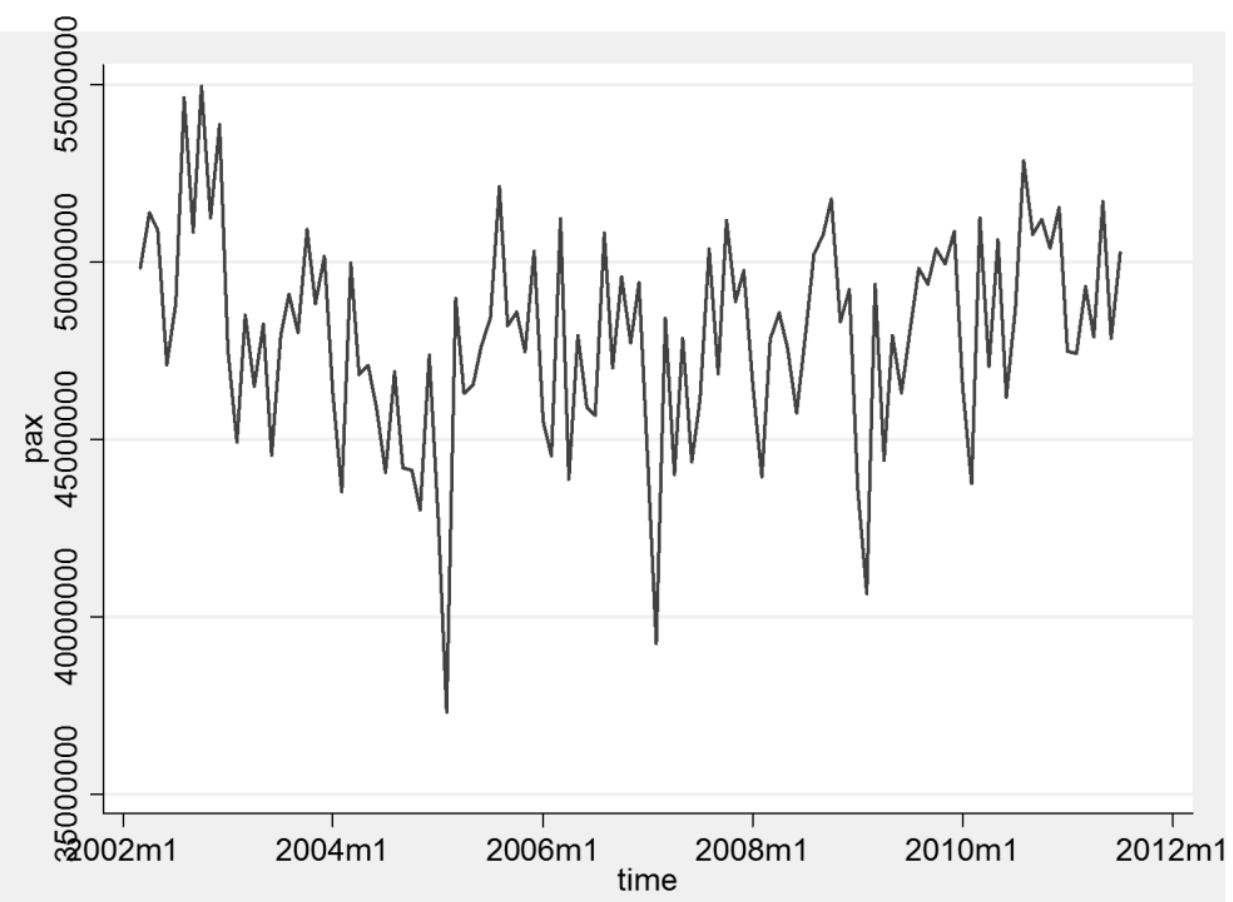

Figura 1 - Comportamento temporal da variável pax

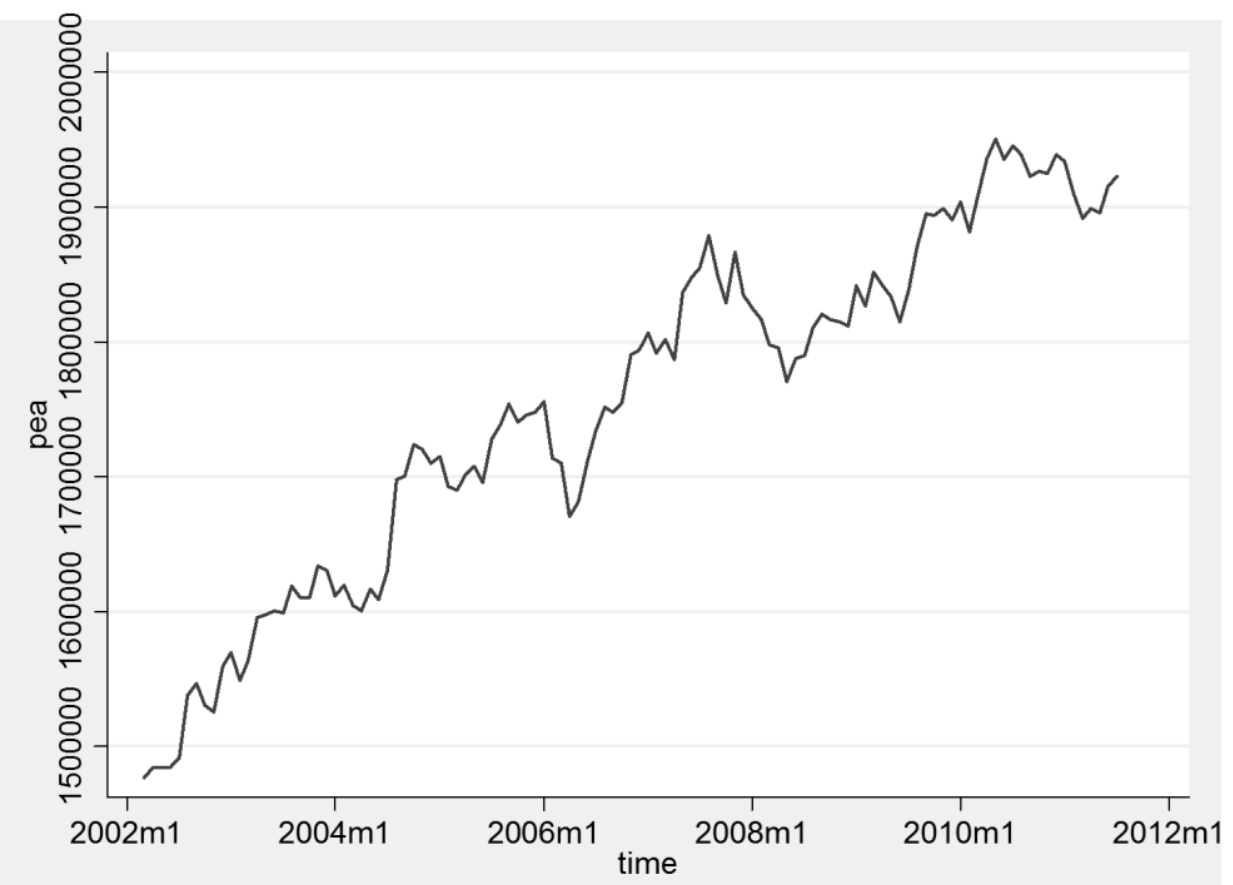

Figura 2 - Comportamento temporal da variável pea 


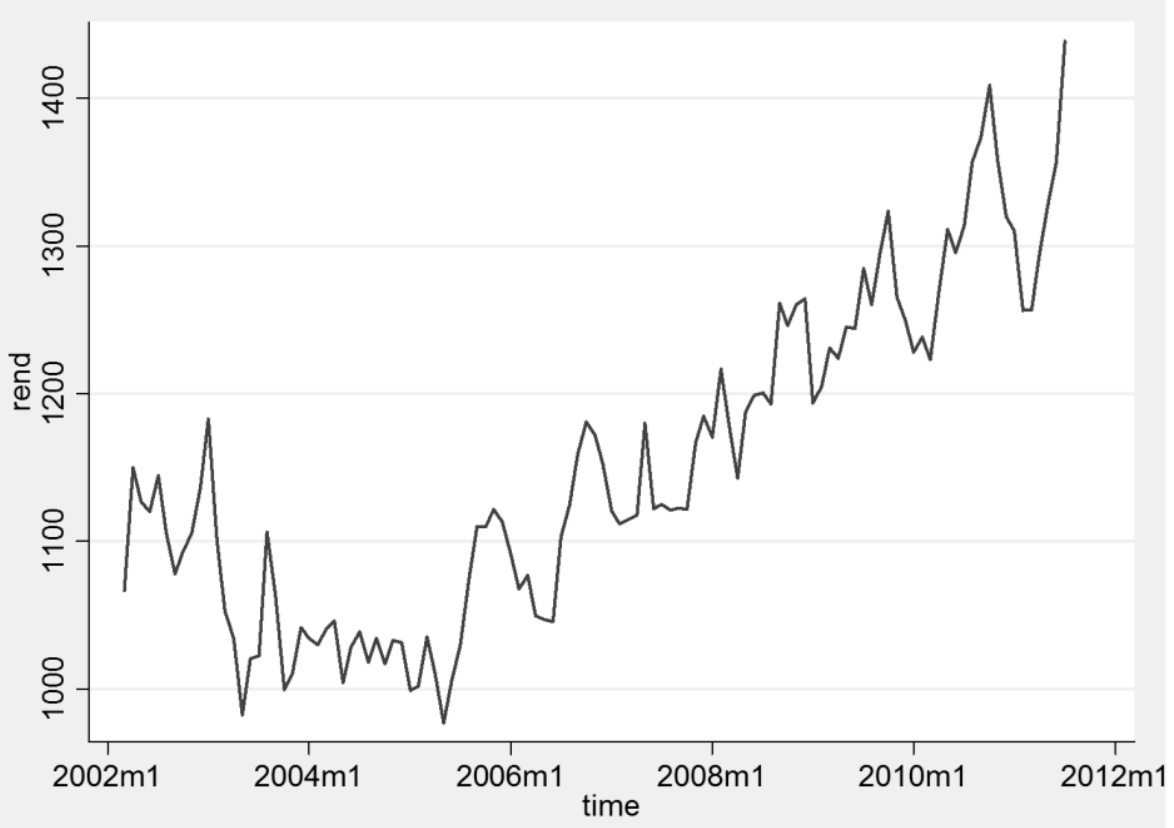

Figura 3 - Comportamento temporal da variável rend

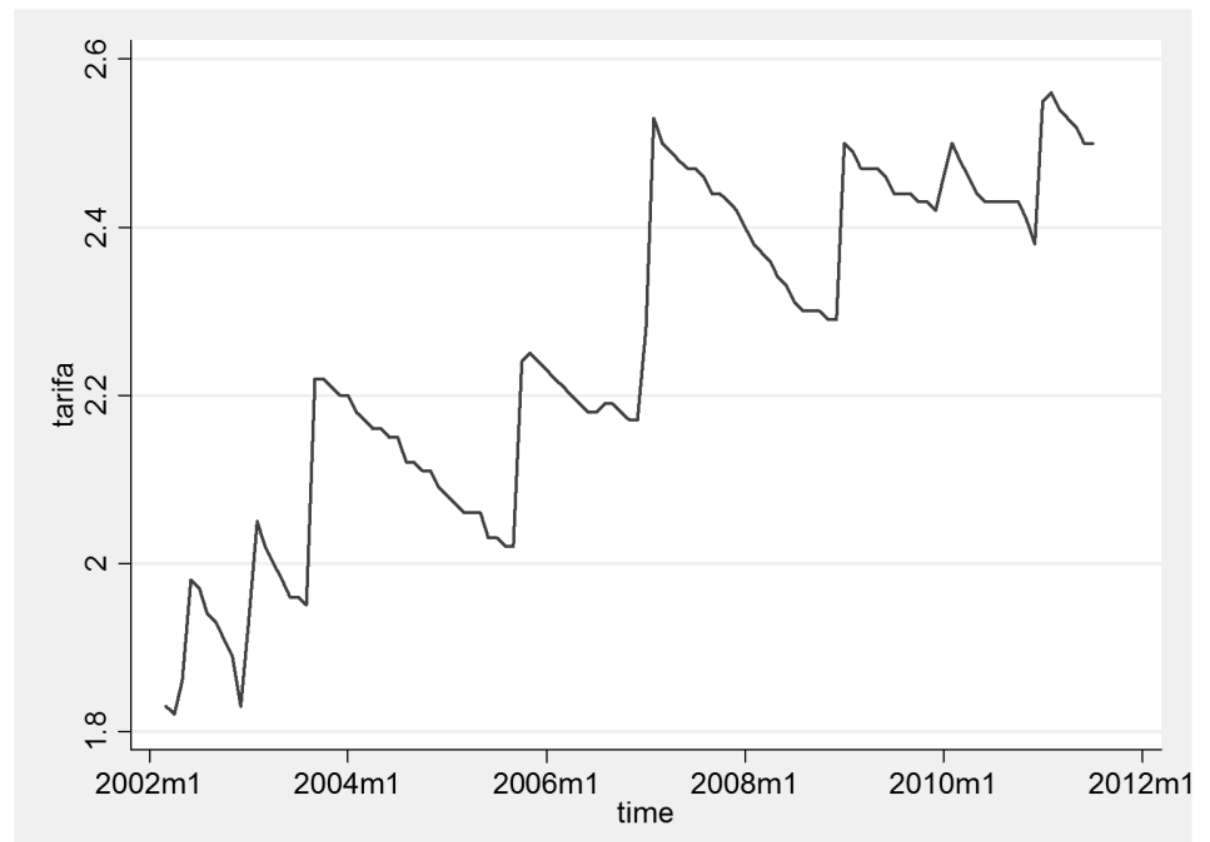

Figura 4 - Comportamento temporal da variável tarifa 
Em continuidade ao processo de análise qualitativa da base de dados, a Tabela 2 apresenta a matriz de correlação para as variáveis analisadas e a Figura 5 apresenta essas correlações na forma de diagrama de dispersão. Observa-se que a quantidade de passageiros transportados é negativamente correlacionada com a tarifa e positivamente correlacionada com a população economicamente ativa e com o rendimento médio, revelando um comportamento de bem normal para o transporte público por ônibus. Apesar dos pequenos valores de correlação de pax com as demais variáveis, os resultados parecem estar coerentes com o entendimento de senso comum do processo gerador de dados.

Tabela 2 - Matriz de correlações

\begin{tabular}{|rrrrr|}
\hline & pax & pea & rend tarifa \\
pax | & 1.0000 & & & \\
pea | & 0.0007 & 1.0000 & & \\
rend | & 0.3121 & 0.7444 & 1.0000 & \\
tarifa | & -0.1069 & 0.8908 & 0.6698 & 1.0000 \\
\hline
\end{tabular}

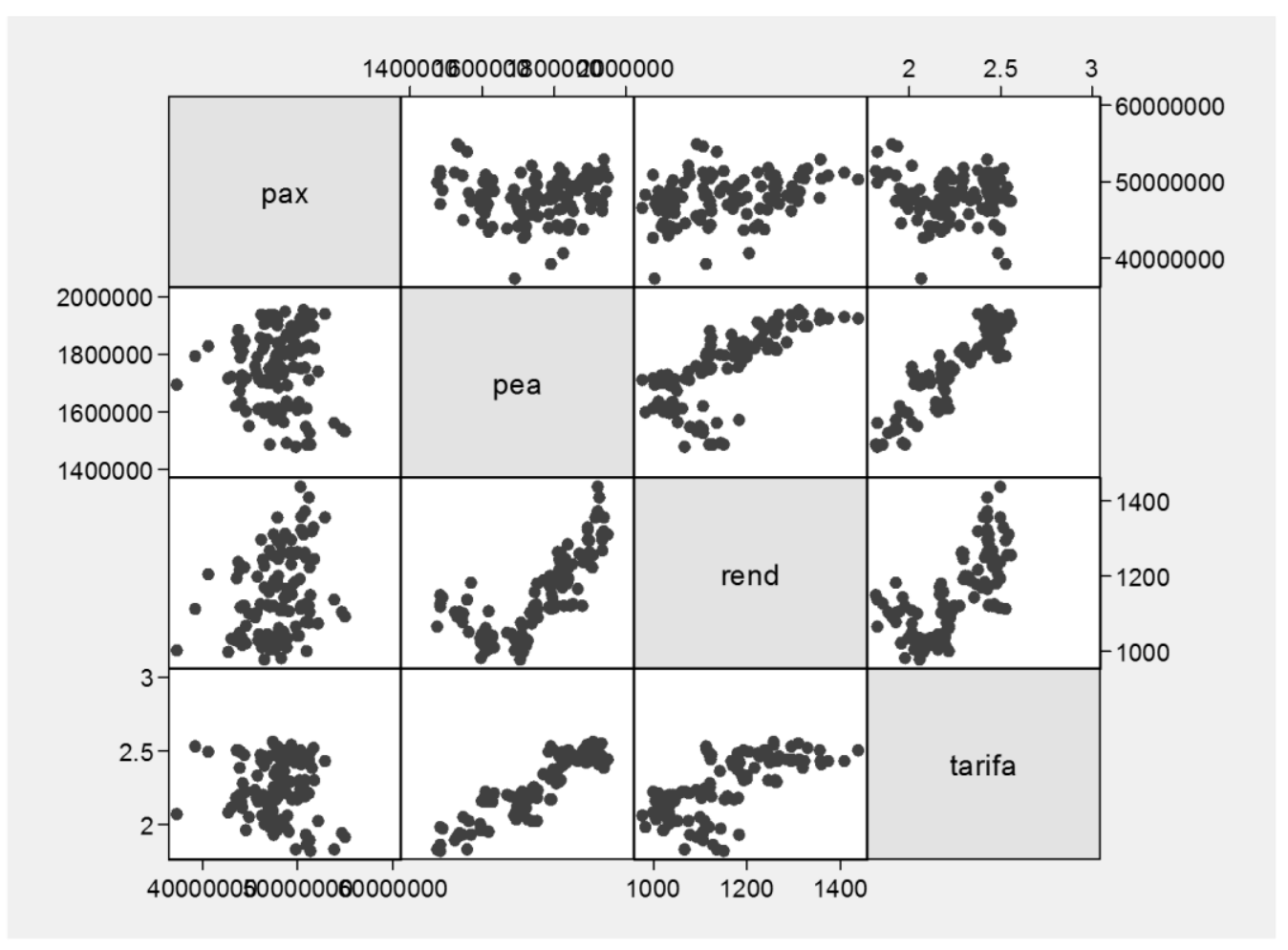

Figura 5 - Diagrama de correlação entre variáveis 


\section{Estudo econométrico}

O estudo econométrico foi realizado de forma a viabilizar a obtenção de um modelo considerado o mais representativo possível do processo gerador de dados, dentro da limitação imposta pela disponibilidade de dados. Assim, foram analisados três modelos de regressão múltipla para a demanda de passageiros por ônibus urbano na cidade de Salvador, cujos resultados foram comparados entre si e embasaram a especificação de um modelo "campeão".

O primeiro modelo considera as variáveis pea, rend e tarifa como variáveis explicativas independentemente, conforme a Equação (1). O segundo modelo considera uma variável agregada (rend_pea) representativa da massa de rendimentos da população, composta pela multiplicação de pea e rend, e tarifa como variáveis explicativas, conforme a Equação (2). Finalmente, o modelo logarítmico apresentado pela Equação (3) resulta da hipótese de que a frequência de viagens para cada membro da população economicamente ativa pode ser representada por um modelo multiplicativo cujas variáveis explicativas são rend e tarifa, conforme Equações (4) e (5). Assim, a quantidade de passageiros transportados pode ser aproximada pela multiplicação da frequência de viagens pelo total de população economicamente ativa.

Todos os modelos foram processados com controle de autocorrelação e heteroscedasticidade e foram introduzidas dummies de sazonalidade e uma variável de tendência. Para o termo aleatório $u$, assume-se a hipótese de média condicional zero e que o mesmo é independente e identicamente distribuído segundo uma Normal de média zero e variância constante. Assim, dada a impossibilidade de realização de um experimento controlado, assumiu-se que os não observáveis, como, por exemplo, comportamento político subjetivo, não tem relação com os observáveis representados pelos regressores. É importante destacar o significado e a força desta hipótese: assume-se, por exemplo, que a evolução tarifária não é impactada de forma sistêmica por aspectos subjetivos de estratégias políticas. 


$$
\begin{gathered}
\text { pax }=\alpha+\beta_{1} \text { pea }+\beta_{2} \text { rend }+\beta_{3} \text { tarifa }+\sum_{i=1}^{12} \beta_{i+3} m_{-} i+u \\
\text { pax }=\alpha+\beta_{1} \text { rend_pea }+\beta_{2} \text { tarifa }+\sum_{i=1}^{12} \beta_{i+2} m_{-} i+u \\
\ln (\text { pax } / \text { pea })=\ln \left(\alpha_{0}\right)+\beta_{1} \ln (\text { rend })+\beta_{2} \ln (\text { tarifa })+\sum_{i=1}^{12} \ln \left(\alpha_{i}\right) m_{-} i+u \\
\text { pax }=\text { pea } \times \text { freq } \\
\text { freq }=\alpha_{0} \times \text { rend }{ }^{\beta_{1}} \times \text { tarifa }^{\beta_{2}} \times \prod_{i=1}^{12} \alpha_{i}{ }^{m_{-} i}
\end{gathered}
$$

Uma vez especificados diferentes modelos, foi realizada a estimação dos parâmetros, cujos resultados são apresentados na Tabela 3. Analisando-se a significância estatística dos parâmetros estimados, bem como a qualidade do ajuste, optou-se pelo modelo apresentado pela Equação (3) como especificação campeã devido a uma série de fatores que serão discutidos a seguir. Através da análise dos resultados detalhados deste modelo, pode-se verificar que as variáveis de rendimento e de tarifa resultaram estatisticamente significantes a $1 \%$ e a $10 \%$, respectivamente, e a qualidade do ajuste foi de 0,807 .

Em todos os modelos, observa-se que o nível de significância das variáveis relacionadas à tarifa foi menor, quando comparado ao das outras variáveis, revelando um menor grau de confiabilidade na existência de relação de causalidade entre tarifa e pax. Isso pode ser explicado pelo fato de a demanda por ônibus urbano ser bastante inelástica, aspecto característico de um bem essencial. Apesar disso, todos os coeficientes relacionados às variáveis de tarifa resultaram negativos, o que é coerente com a teoria da demanda. É possível notar também que, quando as variáveis pea e rend são incluídas de forma independente no modelo, alguns resultados incoerentes são gerados, como o fato de o coeficiente da variável pea ser negativo, apesar de estatisticamente significante a 5\%. Uma possível explicação para isso é a elevada correlação entre as variáveis pea e rend, como mostra a Tabela 2, gerando o problema de multicolinearidade.

A elevada correlação entre as variáveis independentes (regressores) utilizados foi o motivo pelo qual se decidiu especificar modelos com variáveis agregadas (em vez de descartar uma 
delas), com o objetivo de minimizar os problemas resultantes da multicolinearidade. Em consequência, no modelo que considera a massa de rendimentos da população, por exemplo, a variável agregada de pea e rend resultou estatisticamente significante a $1 \%$, apresentando coeficiente positivo. Apesar disso, a qualidade do ajuste desta especificação foi a menor de todas.

A análise de elasticidades para a terceira especificação de modelo revela que, para cada $1 \%$ de aumento no rendimento médio per capita, a demanda cresce $1,44 \%$ e que, para cada $1 \%$ de aumento real no valor da tarifa, a demanda decresce $0,06 \%$ (comportamento inelástico), resultado que contraria as conclusões de Carvalho e Pereira (2012) no que diz respeito à tendência de comportamento elástico da demanda por transporte público urbano desde 2001 (demanda agregada para nove capitais brasileiras). Uma possível justificativa para essa discrepância é a elevada participação do transporte público coletivo por ônibus na matriz modal da cidade de Salvador e da pequena diversificação atualmente existente, conforme descrito na Seção 1, criando uma dependência da população em relação ao transporte por ônibus e uma impossibilidade de fuga para outros modais. Assim, ressalta-se a importância de estudos individuais de demanda para cada cidade em função das especificidades de cada estrutura urbana existente.

Por fim, foi realizada uma análise de sensibilidade para o modelo logarítmico representado pela Equação (3) através da omissão de um dos regressores. Os resultados são apresentados na Tabela 4. Verificou-se que a qualidade do ajuste reduziu quando tanto a tarifa quanto o rendimento foram retirados do modelo e que, em ambos os casos, o regressor mantido resultou estatisticamente significante a $1 \%$. Além disso, pode-se perceber que os coeficientes de rendimento e tarifa resultaram maiores em módulo nos modelos com apenas um regressor, em função do viés resultante da omissão de uma variável relevante. Como a correlação entre as variáveis de rendimento e de tarifa é positiva (Tabela 2), tem-se que, no caso da omissão do regressor lnrend, o viés resulta positivo (correlação entre rendimento e regressando positiva) e, no caso da omissão do regressor lntarifa, o viés resulta negativo (correlação entre tarifa e regressando negativa), o que explica o aumento em módulo dos coeficientes nos modelos com um regressor apenas. 
Tabela 3 - Comparação entre diferentes especificações de modelo

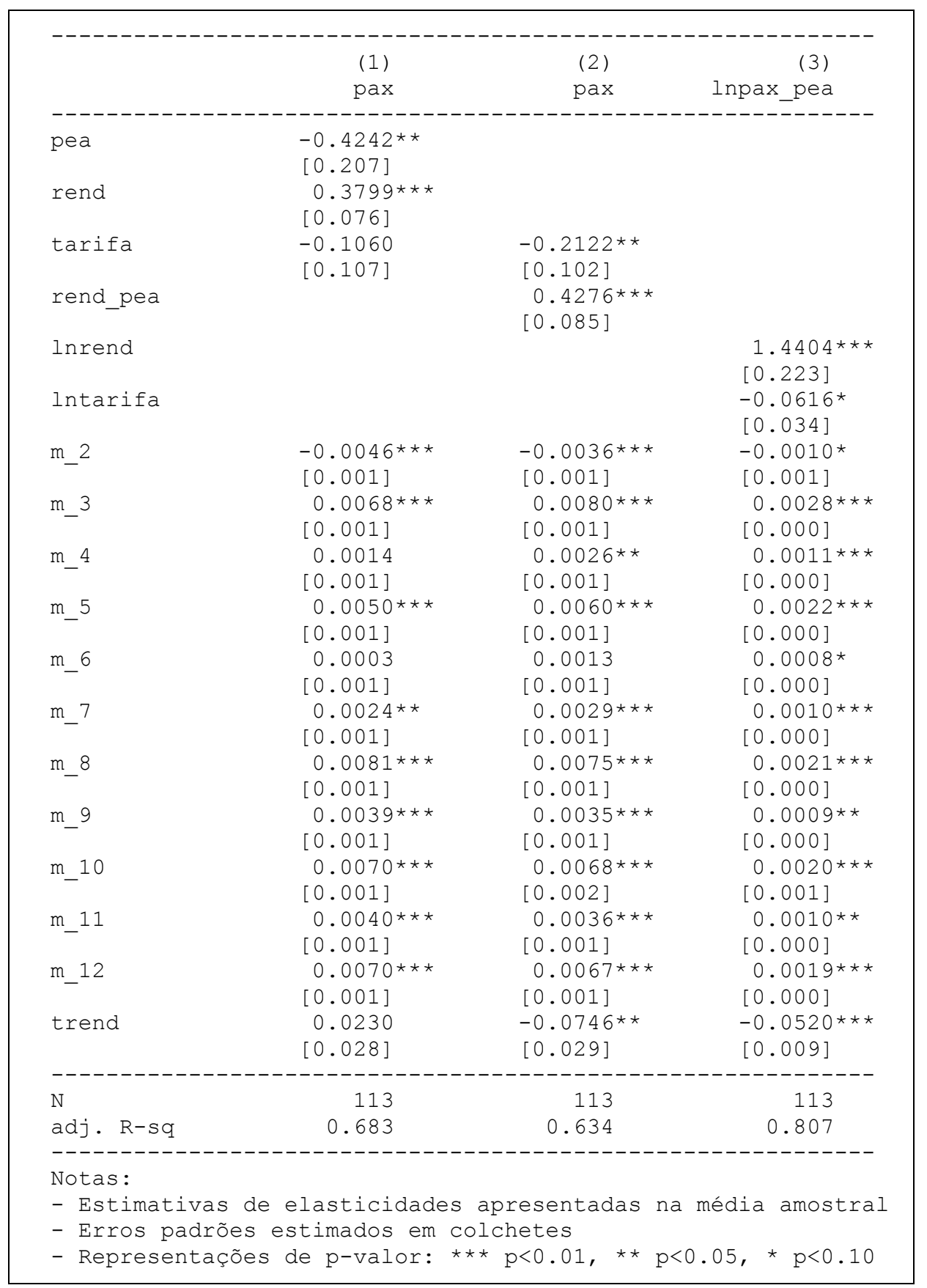


Tabela 4 - Análise de sensibilidade para o modelo logarítmico

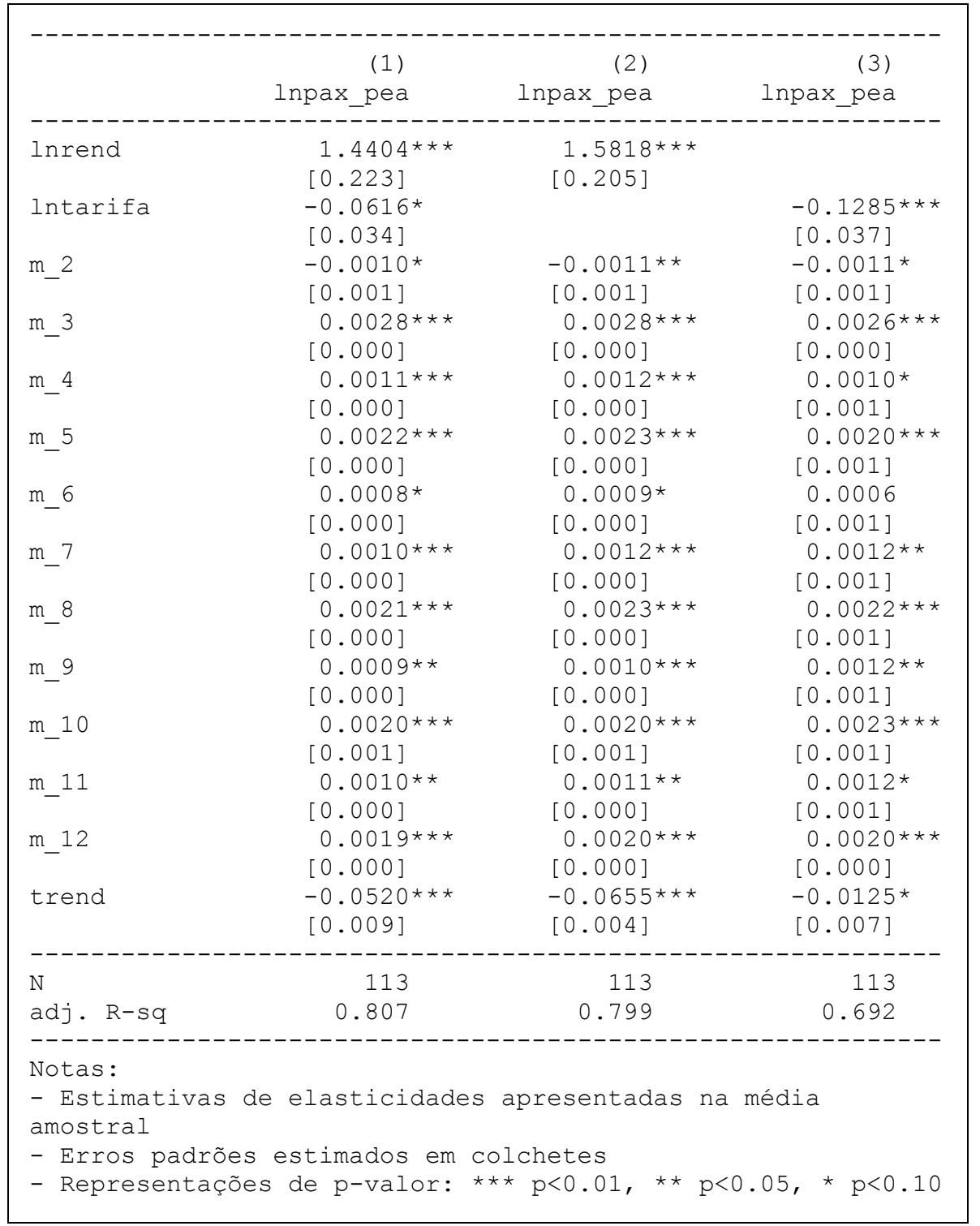




\section{Previsão de demanda}

Uma vez especificado o modelo econométrico, cujo comportamento é apresentado na Figura 6 , foi possível realizar a previsão de demanda por transporte público urbano (ônibus) na cidade de Salvador para um período de 5 anos. Após análise da base de dados e do contexto histórico, foram desenvolvidos cenários de evolução para as variáveis utilizadas. Foram adotadas as seguintes taxas de crescimento ao ano: $3 \%$ para a população economicamente ativa (pea), $4 \%$ para o rendimento médio (rend) e $5 \%$ para o preço da passagem de ônibus (tarifa). As taxas de crescimento para emprego e renda foram estabelecidas com base na análise da conjuntura do mercado de trabalho realizada pelo Instituto de Pesquisa Econômica Aplicada (IPEA, 2012). No caso da tarifa, partiu-se da hipótese de que a tendência de aumento dos custos operacionais do setor será mantida (aumento do preço dos insumos e envelhecimento da frota) e que, em uma análise de curto prazo, as estratégias de regulação do setor ainda não serão capazes de impedir o repasse destes custos para o preço da passagem. A Tabela 5 apresenta os resultados da previsão de demanda por ônibus urbano em Salvador até o ano de 2016.

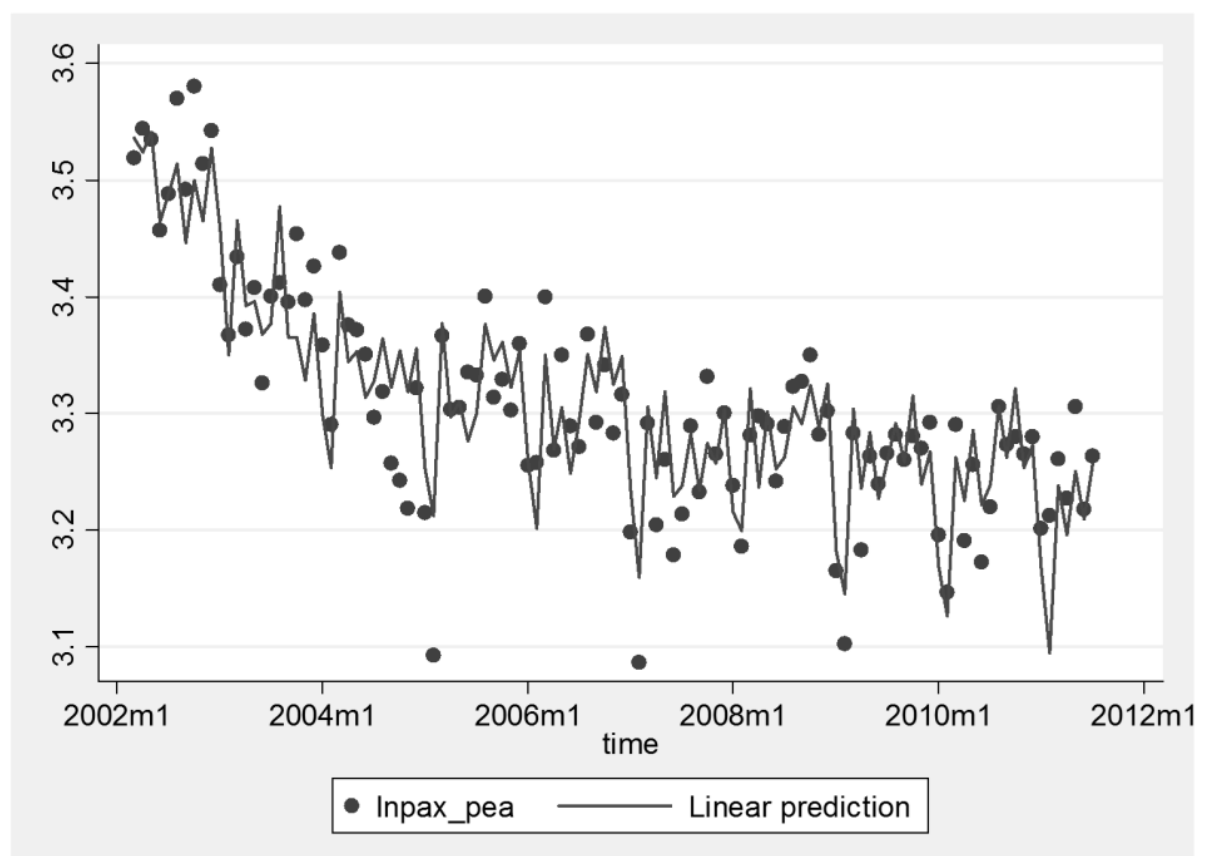

Figura 6 - Comportamento do modelo de previsão de demanda 
Tabela 5 - Previsão de demanda por ônibus urbano em Salvador

\begin{tabular}{|c|c|c|r|r|}
\hline & \multicolumn{3}{|c|}{ Cenários } & \multicolumn{1}{c|}{ Previsão } \\
\hline Variáveis & Pea & rend & Tarifa & Pax \\
\hline Ano-base: 2011 & 1.910 .000 & $1.320,34$ & 2,50 & - \\
\hline 2012 & 1.967 .300 & $1.373,15$ & 2,63 & 66.140 .313 \\
\hline 2013 & 2.026 .319 & $1.428,08$ & 2,76 & 69.086 .984 \\
\hline 2014 & 2.087 .109 & $1.485,20$ & 2,89 & 72.164 .927 \\
\hline 2015 & 2.149 .722 & $1.544,61$ & 3,04 & 75.450 .058 \\
\hline 2016 & 2.214 .213 & $1.606,39$ & 3,19 & 78.811 .486 \\
\hline \multicolumn{4}{|c}{ Fonte: Autor }
\end{tabular}

Observa-se uma previsão de crescimento de 19,2\%, totalizando um aumento de aproximadamente 12,7 milhões de passageiros em 5 anos. Assumindo que o metrô de Salvador transporte 25 mil passageiros por dia na primeira fase (Ibahia, 2012), ainda serão necessários investimentos para ampliação da capacidade do sistema de transporte urbano por ônibus, já que a previsão de término da construção do novo sistema de metrô é de, no mínimo, 4 anos.

É válido ressaltar que esta previsão de demanda foi fundamentada em cenários de evolução da população economicamente ativa e do rendimento médio que podem ser considerados conservadores e que o modelo utilizado, apesar de eleito o melhor dentre os avaliados, não engloba outras variáveis que aparentemente compõem o processo gerador de dados, como, por exemplo, o número de matrículas escolares no município, devido à ausência de dados. Assim, a interpretação dos resultados deve ser realizada levando-se em consideração as limitações expostas.

\section{Conclusão}

Este trabalho teve o objetivo de avaliar o comportamento da demanda por ônibus urbano no contexto da cidade de Salvador através de um estudo econométrico detalhado que viabilizou a discussão de variáveis relevantes e a realização de previsões no curto prazo. É válido observar que a análise e a previsão de demanda no setor de transportes são de fundamental importância para o planejamento de investimentos destinados a garantir a mobilidade necessária ao desenvolvimento das atividades produtivas de uma região. No Brasil, o ônibus é o meio de transporte coletivo predominante na maioria das cidades e, por este motivo, o gerenciamento 
dos transportes no nível urbano depende da realização de análises de demanda e capacidade para este modal.

Após a composição de uma base de dados que foi descrita qualitativa e quantitativamente, foram especificados três modelos econométricos para analisar a influência do tamanho da população economicamente ativa, do rendimento médio per capita e do preço da passagem na demanda, contrapondo-se a modelagem matemática comumente utilizada a uma modelagem oriunda da hipótese de que cada passageiro transportado é consequência da aplicação de um modelo multiplicativo de frequência de viagens sobre cada integrante da população economicamente ativa. Verificou-se que a modelagem desenvolvida promoveu uma significativa melhoria na qualidade do ajuste e que todos os parâmetros resultaram estatisticamente significantes. Após a realização de uma análise de sensibilidade para o modelo desenvolvido e uma vez escolhida a melhor especificação, obteve-se que, para cada $1 \%$ de aumento no rendimento médio per capita, a demanda cresce $1,44 \%$ e que, para cada $1 \%$ de aumento real no valor da tarifa, a demanda decresce $0,06 \%$. Este comportamento inelástico da demanda mostrou-se contrário aos resultados de Carvalho e Pereira (2012), apontando, assim, que as especificidades das estruturas urbanas das cidades são relevantes na análise e que estudos individuais de demanda para cada cidade são necessários.

Por fim, foram realizadas previsões para um horizonte de cinco anos, obtendo-se um crescimento de $19,2 \%$ na quantidade de passageiros até 2016. Considerando a capacidade estimada do trecho do metrô próximo de entrar em funcionamento e a previsão de conclusão das obras dos trechos restantes, conclui-se que são necessários investimentos para ampliação de capacidade de forma a atender o crescimento orgânico da demanda na cidade de Salvador. É importante ressaltar que as previsões foram realizadas para cenários considerados conservadores e que algumas potenciais variáveis explicativas, como, por exemplo, a quantidade de matrículas escolares, não foram testadas na modelagem devido à inexistência de dados, o que pode tornar um pouco mais fraca a hipótese de ausência de relação entre os regressores e os componentes não observáveis. Assim, recomenda-se a análise de novos cenários e a investigação de novas variáveis explicativas em trabalhos futuros. 


\section{Referências}

Carvalho, C. H. R. e Pereira, R. H. M. (2012) Efeitos da variação da tarifa e da renda da população sobre a demanda de transporte público coletivo urbano no Brasil. Transportes, vol. 20, n. 1, pp. $31-40$.

Celestino, S. (2012) Linhas de ônibus de Salvador serão licitadas. Bahia Notícias, 13/4/2012, Salvador.

Fundação Instituto de Pesquisas Econômicas - FIPE (2012) Índice de emprego no setor transporte IDET. Disponível em: www.fipe.org.br. Acesso em: 20 maio 2012.

Holmgren, J. (2007) Meta-analysis of public transport demand. Transportation Research Part A, vol. 41, n. 1, pp. 1021-1035.

Instituto Brasileiro de Geografia e Estatística - IBGE (2012) Sistema IBGE de Recuperação Automática - SIDRA. Disponível em: www.sidra.ibge.gov.br. Acesso em: 20 maio 2012.

Instituto de Pesquisa Econômica Aplicada - IPEA (2012) Mercado de trabalho: conjuntura e análise. 51 ed., Ministério do Trabalho e Emprego, Brasília, DF.

Lopes Filho, J. I. O. (2003) Pós-avaliação da previsão de demanda por transportes no município de Fortaleza. Dissertação (Mestrado em Engenharia de Transportes), Universidade Federal do Ceará, Fortaleza.

Portal iBahia (2012) Soteropolitanos poderão utilizar o metrô no segundo semestre de 2012, garante João Henrique. Portal iBahia, 22/12/2011, Salvador.

Santos, J. L. C. (2012) Desafios para a mobilidade da região metropolitana de Salvador - Bahia. Disponível em: www.nossasalvador.org.br Acesso em: 15 maio 2012.

Sindicato das Empresas de Transporte de Passageiros de Salvador - SETPS (2012a) História do transporte urbano em Salvador. Disponível em: www.setps.com.br. Acesso em: 12 maio 2012.

Sindicato das Empresas de Transporte de Passageiros de Salvador - SETPS (2012b) Salvador Card. Disponível em: <http://www.setps.com.br/>. Acesso em: 12 maio 2012.

Souche, S. (2010) Measuring the structural determinants of urban travel demand. Transport Policy, vol. 17, n. 1, pp. 127-134.

Superintendência de Trânsito e Transporte do Salvador - TRANSALVADOR (2012) Fundetrans. Disponível em: www.transalvador.salvador.ba.gov.br. Acesso em: 18 maio 2012.

Terrabuio Junior, D. J. (2010) Análise da demanda por transporte coletivo em quatro cidades médias do Estado de São Paulo. Dissertação (Mestrado em Engenharia de Transportes), Universidade de São Paulo, São Carlos. 